\title{
A population based pediatric oncology registry in Southern Sweden: the BORISS registry
}

\author{
Thomas Wiebe $^{1} \cdot$ Lars Hjorth $^{1,3} \cdot$ Mercedes Marotta Kelly $^{2} \cdot$ Helena M. Linge $^{1} \cdot$ Stanislaw Garwicz ${ }^{1}$
}

Received: 16 March 2018/Accepted: 25 August 2018/Published online: 6 September 2018

(C) The Author(s) 2018

\begin{abstract}
A population based registry, with the acronym BORISS, was established. It contains all individuals (0-18 years of age at diagnosis) diagnosed with cancer from 1970-01-01 until 2016-12-31 in Southern Sweden. The treatment data has been entered into the registry after confirmation of the diagnosis by the Swedish national cancer registry and updates on vital status from the Swedish population registry. The number of individuals with a pediatric cancer diagnosed during these 46 years are 2928. Of these, 2065 are currently alive and 1882 individuals are 5-year survivors. Data on treatment and malignancy of the 5-year survivors has been collected from medical records and entered into the database. Treatment data contains surgical procedure, target organ of radiation therapy including dose and fractionation, and cytostatic treatment with dose $(\mathrm{mg})$ per body surface area $\left(\mathrm{m}^{2}\right)$ for all cytostatic agents. Data on individuals receiving stem cell treatment is included. The database is unique in that it is population based, contains all individuals and detailed treatment data on all 5-year survivors after childhood cancer in Southern Sweden since 1970. The database has contributed to several academic theses in the field of late effects after childhood cancer. BORISS also supports the Late Effect Clinic at Skåne University Hospital in Lund, Sweden with treatment details enabling a stratified surveillance.
\end{abstract}

Keywords Childhood cancer survivorship $\cdot$ Registry $\cdot$ Population based $\cdot$ Sweden

\section{Introduction}

Survival after childhood cancer has increased dramatically over the last 45 years. Survival past 5 years after diagnosis now averages $80 \%$ in high income countries [1]. Sweden has approximately 350 new annual cancer cases diagnosed up to 18 years of age and approximately 9000 adult longterm childhood cancer survivors (CCS). The number of CCS for Europe is estimated to be 300-500,000, and the number increases by 12,500 each year. An estimated $65 \%$ of these individuals have moderate to severe long term effects of their childhood cancer and the treatment [2]. Late effects after childhood cancer treatment is a growing field

Helena M. Linge

helena.linge@med.lu.se

1 Faculty of Medicine, Department of Clinical Sciences Lund, Pediatrics, Lund University, Lund, Sweden

2 Regional Cancer Center South, Lund, Sweden

3 Department of Clinical Sciences Lund, Pediatrics, Lund University, Skane University Hospital, Lund, Sweden in both pediatric and adult medicine and several large research initiatives have been taken in recent years [3].

The late effects clinic at Skåne University Hospital dates back to 1987 , when it became clinically apparent that cured childhood cancer patients would require long-term follow up. The clinic, a collaboration between the pediatric and adult oncology units, bases its recommendations on national guidelines and details of the primary disease. The collection of details of each individual treatment history became necessary in order to perform adequate surveillance. The collection of such information resulted in the population based BORISS registry.

\section{Methods}

\section{Ethical approvals}

Approval to gather data was sought and received from the central review board within the Council of Skåne. The permit also covered data gathering from patients living in 
the adjacent councils Blekinge, Kronoberg and Southern Halland. These three councils together with Council of Skåne constitutes Southern Sweden with a population of approximately 1.8 million inhabitants. In agreement with the laws governing quality registries, information was collected to monitor and enhance the quality of care provided at Skåne University Hospital. The law does not impose a requirement on any consent from the individual. At the time of diagnosis, the parents of the patients were informed and presented with the possibility of opting out from several quality registries.

\section{Data collection}

All individuals in Southern Sweden with a cancer diagnosis occurring between the ages of $0-18$ years of age from 1970-01-01 -2016-12-31 were identified in the national cancer registry. The starting point of enrollment of patients into the registry was chosen due to the low survival rates of childhood cancer before 1970. Since its start in 1958, Swedish law mandates that all cancer cases be reported to the national registry which registers all cancer diagnoses (primary and subsequent) but not details on treatment. The vital status and personal details of the childhood cancer patients were retrieved from the Swedish population registry. Together this data formed the basis for the manual data collection of treatment history and details of the primary malignancy found in the medical records of each individual. In order for the treatment data to be collected and entered into BORISS, the medical records were manually gathered from the archives of the children's clinic in Lund. Records were also found in the departments of Neurosurgery, Pediatric surgery, Medicine, Oncology and Pathology in Lund and in other hospitals in Southern Sweden.

The diagnosis of a malignancy was verified by an experienced pediatric oncologist (TW), by assessment of the pathology report. The diagnosis of malignancy is coded according to ICD-7, ICD-9, C24, ICD-O version 3 and ICD-10. The registry contains 219 different histological diagnoses, divided in 12 categories according to ICCC. Details of chemotherapy were extracted from prescription documents and later on from separate chemotherapy records. The dates and administration routes of all chemotherapy was recorded. All cytostatic agents (conventional drugs and more recently introduced drugs e.g. tyrosine kinase inhibitors, protein kinase inhibitors and antibodies) were recorded. The chemotherapy drugs $(\mathrm{n}=91)$ are coded by a 3-digit number. Cumulative doses of each drug $\left(\mathrm{mg} / \mathrm{m}^{2}\right.$ body surface area) were calculated. From the Radiation clinic, details of target organ(s), total irradiation dose $(\mathrm{Gy})$ and fractionation was gathered. The target organ which received radiation therapy is coded by a 3-digit number and the target list covers 150 targets. When surgery was performed, details of the procedure, microscopic surgical margins, removal of organ(s) or an extremity, if any, were recorded. For stem cell treatment, details of conditioning therapy (with chemotherapy and/or total body irradiation), and dates of the procedure were recorded.

All entered data was cross-checked by two separate individuals. The registry contains personal data, diagnosis (in plain text and in code; ICD-7, ICD-9, C24, ICD-10 and ICD-0 version 3), and date of diagnosis. Phenotypic and cytogenetic data for leukemia, as well as cytogenetic aberrations with regards to solid tumors were gathered from medical records. Where available, data was recorded on other serious diseases, previous treatments, constitutional chromosomal aberrations, and other possible immunosuppressive treatments (pre-dating the cancer diagnosis), as was heredity for malignancies, and data on relapses. By annual updating of the database from the national cancer registry and the population registry, the development of secondary and subsequent primary neoplasms and vital status, are obtained.

Prospective collection of treatment data is carried out from 2016-01-01 and onwards under the governance of the Council of Skåne.

\section{Data access}

Before any data can be accessed for research purposes, an approved ethical permit from the Regional Ethical review board, as well as a permission from the Council of Skåne must be obtained. Data can be made available through collaboration with researchers affiliated with Skåne University Hospital or Lund university based on their knowledge of the data, its collection, purpose, and limitations. The cross-border sharing of personal data is under review due to the General Data Protection Regulation all inquiries must take into account the developments in interpretation of the new regulation. Treatment details are available to the late effects clinic in Lund as part of regular follow-up health care.

\section{Technical aspects}

The database was originally built as a Microsoft Access database with 2 parts: an application for data entry and a separate database for data storage. Controls of data entries were put in place for quality assurance of individual fields and to maintain coherence between different fields. The database storage was placed on a central server with restricted access. The database was modernized to an SQL database in 2017, and a new web based registration form was constructed preserving the original structure. An 
activity $\log$ was added to keep track of registration activities. The data is secured based on user membership in active directory user groups.

\section{Results}

The population-based BORISS registry contains all individuals with a first primary neoplasm diagnosed between 1970-01-01 and 2016-12-31 being 0-18 years of age at diagnosis, in total 2928 individuals. It contains complete treatment data on 2065 currently living individuals out of which 1882 individuals who are 5-year survivors. The oldest living person whose data is registered was born in 1953. The distribution of diagnoses according to ICCC [4], among the 5-year survivors $(\mathrm{n}=1882)$ and the gender distribution is shown in Table 1. Descriptive data of the distribution of the survivors' ages (0-65 years of age) and time since diagnosis (5-47 years) is shown in Table 2. Table 2 also shows the number of individuals which have received different treatment modalities.

\section{Discussion}

Southern Sweden has had an active presence in pediatric oncology since the late 1960s. Retrospective collection of data from childhood cancer patients for this study was time consuming, especially for the early decades where procurement of the paper charts was necessary. A single chart could take up to $8 \mathrm{~h}$ to extract data from. The chemotherapy records remained as paper documents until recently when digitalization became a step forward. The work was facilitated by well-organized staff at the regional archives, where the medical charts are stored.

The BORISS registry has already contributed to several academic theses at Lund University, Sweden [5-8]. BORISS also supports the late effects clinic at Skåne University Hospital in Lund, Sweden with treatment details enabling a stratified surveillance. In comparison to other cohorts, BORISS covers a region (rather than a country) with the advantage of being population-based building on the by-law-mandated national cancer registry (all cancers).

On a national level, a registry with a focus on treatment data and long-term follow-up was started in 2012 but to date it contains only $1 / 3$ of eligible patients with coverage starting only in the 1980s. At the international level several initiatives aim at providing childhood cancer survivors with adequate and appropriate long-term medical followup. The EU-funded project PanCareSurFup (2011-2017) established a large cohort $(\mathrm{n}=115,000)$ of childhood cancer survivors with almost 84,000 five-year survivors [9]. On a subset of these, treatment data was collected from historic medical charts with the focus of examining cardiotoxicity, late mortality and second primary neoplasms. The individuals were identified by outcome and then traced back to historical records.

In Scandinavia, a large project, Adult Life after Childhood Cancer in Scandinavia (ALiCCS) is also aimed at examining late effects in childhood cancer survivors [10]. The focus areas include diabetes mellitus, cardiopulmonary disorders, endocrine disorders and renal and gastrointestinal disorders, and as in the other recent initiatives the treatment data has had to be collected retrospectively on a patient-by-patient basis. The data collection phase (2010-2015) is finished and analyses are ongoing. The outcome groups will be compared to a statistically selected sub-cohort representing the entire population of CCS in the Nordic countries.

In the US, there are several cohorts of long term survivors after childhood cancer $[2,11]$. These cohorts have contributed with valuable knowledge to the late effects field but the findings may be limited in impact as they are not population based. They can hence only suggest the true number of individuals to be expected to be affected by late effects.

\section{Limitations and future prospects}

The number of individuals with rare cancer diagnoses in BORISS will, as expected, be small. Specific consideration should be given when conducting studies, in order not to over-interpret any findings. Other potential limitations of the data in BORISS include the quality of the information in the medical records, in particular family medical history. Complications of treatments e.g. graft-versus-host disease, surgical complications, number of placements of central administration route devices, and details of blood transfusions are not included. Non-typical childhood cancers like malignant melanoma and thyroid cancers were included in the database whereas cervical dysplasias and mola hydatiformis were excluded.

The BORISS registry was formed as a quality registry and this, together with data retrieval from the by-law mandated entry into the national cancer registry, is the explanation for the complete coverage rate. The longitudinal BORISS cohort will enable further research within various fields in pediatric and adult medicine. Ongoing studies aim to determine details of cardiomyopathy and cognitive effects after childhood cancer treatment. By use of artificial intelligence, an ongoing study aims to determine previously unknown associations between treatment history and outcomes. 
Table 1 Number of 5-year survivors according to diagnostic group

\begin{tabular}{|c|c|c|}
\hline \multirow[t]{2}{*}{ Diagnostic group } & \multirow[t]{2}{*}{ ICD-10 } & $\begin{array}{l}5 \text { year } \\
\text { survivors }(\mathrm{n}=)\end{array}$ \\
\hline & & Female \\
\hline
\end{tabular}

\section{Group I Leukaemias}

Ia Acute lymphoid

Pre-B

B cell

T-cell

Non-specified

Ib Acute myeloid

Ic Chronic myeloid
Group II Lymphomas
IIa Hodgkin lymphomas
IIb Non-Hodgkin
lymphomas

IIc Burkitt lymphomas

IId Lymphoreticular neoplasms. Langerhans cellhistiocytos

\section{Group III Central}

nervous system

Intracranial

Intraspinal

Meningeas

Opticus gliomas

Acusticus gliomas

Hypophyseal adenomas

Hypophyseal

craniopharyngeomas

Corpus pineal neoplasms

Group IV Neuroblastoma

Neuroblastoma in sympathetic nervous ganglion

Neuroblastom in adrenal medulla

Sarcomas of peripheral nerves

Group V Retinoblastoma

Group VI

C91.0, C91.7

$329 \quad 144$

$243 \quad 111$

80

$30 \quad 5$

$48 \quad 28$

C92.0, C92.3, C92.4, $\quad 55 \quad 32$

C92.5, C92.9, C93.0,

C93.7, C94.0, C94.2

C92.1

C81.0-C81.9

C83.0-C83.9,

C84.5, C85.8, C86.6

except C83.7 (Burkitt)

C83.7

C96.0

$5 \quad 5$

$110 \quad 46$

$43 \quad 14$

$35 \quad 7$

$42 \quad 17$

$492 \quad 213$

C71.0-C71.9

C72.0-C72.9

C70.0-C70.1

$\mathrm{C} 72.3$

$\mathrm{C} 72.4$

C75.1

C75.2

C75.3

C47.0-C47.9

C74.1

C47.0-C47.9

C69.2

C64.9

C64.9

Wilms' tumour

Other renal tumours

C64.9

Group VII

C22.2

Hepatic tumours

Hepatoblastoma

Group VIII

Malignant bone tumours
Table 1 (continued)

\begin{tabular}{|c|c|c|c|}
\hline \multirow[t]{2}{*}{ Diagnostic group } & \multirow[t]{2}{*}{ ICD-10 } & \multicolumn{2}{|c|}{$\begin{array}{l}5 \text { year } \\
\text { survivors }(\mathrm{n}=)\end{array}$} \\
\hline & & Total & Female \\
\hline VIIIa Osteosarcomas & $\begin{array}{l}\text { C40.0-C40.9 C41.0- } \\
\text { C41.9 }\end{array}$ & 34 & 17 \\
\hline VIIIb Chondrosarcomas & $\begin{array}{l}\text { C40.0-C40.9 C41.0- } \\
\text { C41.9 }\end{array}$ & 3 & 1 \\
\hline $\begin{array}{l}\text { VIIIc Ewing sarcomas } \\
\text { (bone and soft tissue) }\end{array}$ & $\begin{array}{r}\text { C40.0-C40.9 C41.0- } \\
\text { C41.9 C49.0-C49.9 }\end{array}$ & 33 & 17 \\
\hline $\begin{array}{l}\text { VIIId Other malignant } \\
\text { bone tumours }\end{array}$ & $\begin{array}{l}\text { C40.0-C40.9 C41.0- } \\
\text { C41.9 }\end{array}$ & 24 & 9 \\
\hline $\begin{array}{l}\text { Group IX Soft tissue } \\
\text { sarcomas }\end{array}$ & C49.0-C49.9 & 147 & 58 \\
\hline \multirow[t]{3}{*}{ Rhabdomyosarcomas } & Embryonal & 27 & 9 \\
\hline & Alveolar & 7 & 4 \\
\hline & Non-specified & 2 & 2 \\
\hline $\begin{array}{l}\text { Other soft tissue } \\
\text { sarcomas }\end{array}$ & & 111 & 43 \\
\hline $\begin{array}{l}\text { Group X Germ cell } \\
\text { tumours }\end{array}$ & & 73 & 33 \\
\hline $\begin{array}{l}\text { Xa Intracranial and } \\
\text { intraspinal germ cell } \\
\text { tumours }\end{array}$ & & \multicolumn{2}{|c|}{$\begin{array}{l}\text { Included in } \\
\text { group III }\end{array}$} \\
\hline $\begin{array}{l}\text { Xb Germ cell tumours } \\
\text { (not intracranial, } \\
\text { intraspinal, ovary nor } \\
\text { testis) }\end{array}$ & C49.0-C49.9 & 24 & 15 \\
\hline \multicolumn{4}{|l|}{$\begin{array}{l}\text { Xc Malignant germ cell } \\
\text { tumours }\end{array}$} \\
\hline In testis & C62.0-C62.9 & 31 & 0 \\
\hline In ovary & C56.9 & 18 & 18 \\
\hline $\begin{array}{l}\text { Group XI Other } \\
\text { malignant epithelial } \\
\text { neoplasms and } \\
\text { malignant melanomas }\end{array}$ & & 103 & 68 \\
\hline $\begin{array}{l}\text { XIa Adrenal cortical } \\
\text { carcinoma }\end{array}$ & C74.0 & 3 & 1 \\
\hline XIb Thyroid carcinomas & C73.9 & 52 & 41 \\
\hline $\begin{array}{l}\text { XIc Nasopharyngeal } \\
\text { carcinomas }\end{array}$ & C11.9 & 4 & 1 \\
\hline $\begin{array}{l}\text { XId Malignant } \\
\text { melanomas }\end{array}$ & C43.0-C43.9 & 44 & 25 \\
\hline $\mathrm{XI}$ e-f & & $\begin{array}{r}\text { Includ } \\
\text { Grou }\end{array}$ & $\begin{array}{l}\text { ed in } \\
\text { p XII }\end{array}$ \\
\hline $\begin{array}{l}\text { Group XII Other } \\
\text { malignant neoplasms }\end{array}$ & & 96 & 54 \\
\hline
\end{tabular}

\section{Concluding remarks}

Motivated by the clinical need to readily be able to access the primary treatment data, and the vision of facilitating research of the underlying causes of late effects, the 
Table 2 Distribution of all survivors according to age groups, time since diagnosis, and number of individuals according to treatment modality

\begin{tabular}{|c|c|c|}
\hline \multirow[t]{2}{*}{ Distributions all survivors } & \multicolumn{2}{|l|}{ Total (female) } \\
\hline & $2065(968)$ & \\
\hline & Age Groups & $\begin{array}{c}\text { (total } \\
n=)\end{array}$ \\
\hline & $0-14$ & 334 \\
\hline & $15-19$ & 248 \\
\hline & $20-40$ & 960 \\
\hline & $40-65$ & 523 \\
\hline & $\begin{array}{r}\text { Years since } \\
\text { diagnosis }\end{array}$ & $\begin{array}{c}\text { (total } \\
n=)\end{array}$ \\
\hline & $5-9$ & 338 \\
\hline & $10-14$ & 292 \\
\hline & $15-19$ & 253 \\
\hline & $20-24$ & 238 \\
\hline & $25-29$ & 206 \\
\hline & $30-34$ & 196 \\
\hline & $35-39$ & 198 \\
\hline & $40-44$ & 102 \\
\hline & $45-47$ & 59 \\
\hline & $\begin{array}{l}\text { 5-47 years since } \\
\text { diagnosis Sum: }\end{array}$ & 1882 \\
\hline & $\begin{array}{l}\text { Not yet 5-year } \\
\text { survivors. Sum: }\end{array}$ & 183 \\
\hline Treatment modality & $\begin{array}{l}\text { Total number } \\
\quad(\text { female })\end{array}$ & \\
\hline Surgery (including biopsies) & $1441(675)$ & \\
\hline Radiotherapy & $594(263)$ & \\
\hline Chemotherapy & 1049 (475) & \\
\hline Stem cell transplantation & $94(42)$ & \\
\hline Autologous & $39(16)$ & \\
\hline Allogenic & $55(25)$ & \\
\hline $\begin{array}{l}\text { Monoclonal Antibodies } \\
\text { (Mabthera, Avastin, Cetuximab, } \\
\text { Gemtuzumab) }\end{array}$ & $12(5)$ & \\
\hline $\begin{array}{l}\text { Tyrosine kinase inhibitors (Erlotinib, } \\
\text { Imatinib, Dasatinib, Nilotinib) }\end{array}$ & $11(6)$ & \\
\hline
\end{tabular}

collection of data resulted in a population based registry in Southern Sweden. Key factors in establishing the registry were: the use of personal identification numbers in Sweden, the by law mandated entry of cancer diagnoses into the national cancer registry and the foresight of the pioneers in the field with a long-term dedication to finalize the task.

Acknowledgements First and foremost, the long standing and dedicated efforts of Ingemar Andersson in gathering the medical records, is gratefully acknowledged. The pro bono work of constructing web BORISS, carried out by Patrik Eriksson and Jim Larsson (TIETO) is acknowledged. This work was supported financially by
Barncancerfonden, Crafoordska stiftelsen, funds at the Medical Faculty at Lund University, SUS Forskningsfonder and Armec Lindebergs stiftelse. The generous support from engaged colleagues is gratefully acknowledged.

\section{Compliance with ethical standards}

Conflict of interest The authors declare that they have no conflict of interest.

Open Access This article is distributed under the terms of the Creative Commons Attribution 4.0 International License (http://creative commons.org/licenses/by/4.0/), which permits unrestricted use, distribution, and reproduction in any medium, provided you give appropriate credit to the original author(s) and the source, provide a link to the Creative Commons license, and indicate if changes were made.

\section{References}

1. Gatta G, Botta L, Rossi S, Aareleid T, Bielska-Lasota M, Clavel J, et al. Childhood cancer survival in Europe 1999-2007: results of EUROCARE-5-a population-based study. Lancet Oncol. 2014;15(1):35-47.

2. Oeffinger KC, Mertens AC, Sklar CA, Kawashima T, Hudson MM, Meadows AT, et al. Chronic health conditions in adult survivors of childhood cancer. $N$ Engl $J$ Med. 2006;355(15): 1572-82.

3. Hjorth L, Haupt R, Skinner R, Grabow D, Byrne J, Karner S, et al. Survivorship after childhood cancer: PanCare: a European Network to promote optimal long-term care. Eur J Cancer. 2015;51(10):1203-11.

4. Steliarova-Foucher E, Stiller C, Lacour B, Kaatsch P. International classification of childhood cancer, third edition. Cancer. 2005;103(7):1457-67.

5. Mörse H. Anti-Müllerian hormone as a marker of ovarian reserve in girls before, during and after treatment for childhood cancer. Doctoral Thesis (compilation). Lund: Lund University, Faculty of Medicine; 2017.

6. Romerius P. Reproductive function in male childhood cancer survivors. Doctoral Thesis (compilation). Lund: Lund University, Faculty of Medicine; 2010. p. 137.

7. Follin C. Late complications of childhood acute lymphoblastic leukaemia (ALL), with special reference to hormone secretion, cardiovascular risk and bone health. Doctoral Thesis (compilation). Lund: Lund University, Faculty of Medicine; 2010. p. 142.

8. Einarsson E-J. Late effects on hearing and balance after treatment for childhood cancer. Doctoral Thesis (compilation). Lund: Lund University, Faculty of Medicine Otorhinolaryngology, Clinical Sciences; 2014. p. 198

9. Grabow D, Kaiser M, Hjorth L, Byrne J, Alessi D, Allodji RS, et al. The PanCareSurFup cohort of 83,333 five-year survivors of childhood cancer: a cohort from 12 European countries. Eur J Epidemiol. 2018;33(3):335-49.

10. Asdahl PH, Winther JF, Bonnesen TG, De Fine Licht S, Gudmundsdottir T, Anderson H, et al. The Adult Life After Childhood Cancer in Scandinavia (ALiCCS) study: design and characteristics. Pediatr Blood Cancer. 2015;62(12):2204-10.

11. Armenian SH, Landier W, Hudson MM, Robison LL, Bhatia S. COG Survivorship and Outcomes Committee. Children's Oncology Group's 2013 blueprint for research: survivorship and outcomes. Pediatr Blood Cancer. 2013;60(6):1063-8. 